\title{
Carbon Stock And Spatial Dynamics In Natural Forests Of Awi Zone, Amhara Region, Northwestern Ethiopia: Implication For Climate Change Mitigation And Adaptation
}

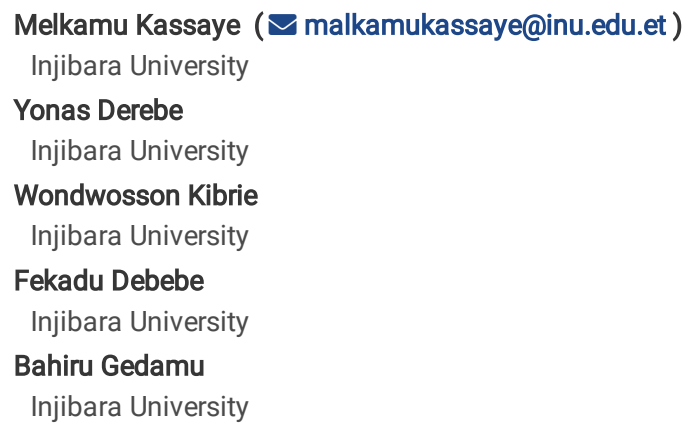

Research Article

Keywords: carbon stock, environmental gradient, natural vegetation, woody biomass, Awi Zone

Posted Date: March 22nd, 2022

DOI: https://doi.org/10.21203/rs.3.rs-1365934/v2

License: (c) (1) This work is licensed under a Creative Commons Attribution 4.0 International License. Read Full License 


\section{Abstract}

Background: As a mitigation measure of climate change, the natural forest plays a key role in controlling the carbon cycle and ecosystem stability through sequestrating the carbon dioxide. However, there have been limited scientific investigation and communication of the potential carbon stock potential of natural forest resources with the global community. Therefore, inventory and estimation of stocks and fluxes of carbon from natural vegetation under different forest communities and different environmental patterns should be done and communicated to the global community for conservation and to get appropriate credit. To do this, 9 forest communities in different agroecology were selected areas of Awi Zone, Northwest Ethiopia. To this end, 76 quadrates with 20meter*20meter quadrate size 200meter distance within quadrates and transect lines Diameter, height, and environmental gradient data were collected and analyzed with R Ver.3.1, XLSTAT, and SPSS Ver.25.

Result: There was a significant difference $(\mathrm{p}<0.029)$ of above and belowground biomass, carbon stock, carbon dioxide sequestration potential, and soil organic carbon across forests communities, slope, altitude, aspect, and agro-ecologies. 'Saharakani' forest has the highest carbon stock as the overall pool. Highland forest communities had a better overall carbon pool. In terms of slop gradient, low slope gradient has recorded the highest allover carbon pool followed by a steep slope and lower slope. In altitude gradient all over carbon, the pool has in decreasing order with increasing of altitude. South facing had the highest carbon stock as overall pools followed by east-facing and west-facing and the least is north facing. Lowland forests had better Soil organic carbon followed by highland and mid-altitude forests. Carbon stock as an overall pool is especially dynamics within environmental patterns.

Conclusion: There is a huge amount of carbon stock in the natural forest in the study area which has a great potential in carbon dioxide sequestration which mitigates the crisis of climate change. However, appropriate credit was not given yet for this natural forest and the resources are continuously declining. Thus, first of all, urgent conservation is required, and then further plan-based sustainable conservation should work should be done for successfully ecologically climate change mitigation.

\section{Background}

Natural disasters specifically climate change is a global environmental crisis mainly as a result of deforestation and forest degradation. Degradation and overexploitation of natural resources specifically natural vegetation make the natural imbalance. This means climate change resulted in global warming, melting of ice (frequent flood) and fire occurrence, and repeated droughts. This is a global headache problem that receiving serious attention [1].

Climate change becomes a global agenda even for the well-developed world and it is one of the core environmental, economic, and political issues. It is anthropogenic cause natural disaster which is difficult to regress and it may persist. Two important countermeasures are mitigation and adaptation to cope with this natural disaster. As a mitigation measure, forests play a key role by controlling the carbon cycle and ecosystem stability by sequestering the $\mathrm{CO}_{2}$ in the atmosphere and sinking as a carbon form [2]. Forest vegetation reduces the main causes of climate change which is greenhouse gases by reducing the concentration in the atmosphere [3].

The climate change mitigation options with afforestation and reforestation as carbon capture and storage have been one of the most promising greenhouse gas reductions. It shows great potential and significance in the reduction of greenhouse gas emissions from deforestation and fossil burning [4]. Therefore, forests play a key ecosystem role in balancing nature with greenhouse gas reductions through carbon sequestration [5].

Ethiopia as a tropical country has vital natural vegetation even if it is cleared and degraded with a time frame that plays a significant role in the global carbon cycle [6]-[8]. Forest vegetation's Ethiopian landscape draw carbon dioxide from the atmosphere and store part of that in their wood for the rest of their lifetime and a little beyond [9]. The natural vegetation stores carbon both above and below ground as biomass in different plant parts, reducing the atmospheric $\mathrm{CO}_{2}$ that is a means of global warming [9].

However, it is not well scientifically evaluated and communicated on how much carbon is stored in a forest with different agro-ecologies and different environmental patterns with the global community that faces climate change specifically in Ethiopia. Also, inventory and estimation of stocks and fluxes of carbon from natural vegetation under different forest communities and different environmental patterns should be evaluated and communicated to the global community for conservation and to get appropriate credit [1]. Therefore, this research was mainly aimed to evaluate the carbon pool of woody species biomass in different forest communities at different environmental gradients at different agro-ecologies.

\section{Methods}

\section{Study area description}

The study was conducted in the Awi zone which is one of the administrative zones in the Amhara region located in between $11^{\circ}$ to $10^{\circ} 85^{\prime} \mathrm{N}$ latitude and $36^{\circ} 39^{\prime} 60^{\prime \prime}$ to $36^{\circ} 57^{\prime} \mathrm{E}$ longitude. Its altitude ranges from 600 to $3500 \mathrm{~m}$. ab. sl. with 1750 mean annual rainfall and $17^{\circ} \mathrm{C}$ to $27^{\circ} \mathrm{C}$ temperature. Topographically speaking, Awi is relatively flat and fertile (Fig. 1).

Most of the Awi zone is Woina Dega (72\%) followed by Dega (17\%) and Kolla (11\%). The area ranges from 700 to $2900 \mathrm{~m}$. ab. sl in altitude and it is the area having better annual rainfall distribution ( 800 to $2700 \mathrm{~mm} /$ year) in the Amhara region. The temperature of the area ranges from 15 to $24{ }^{\circ} \mathrm{C}(\mathrm{Table} 1)$. 
Table 1

Climate and agro-ecology of the study area [10]

\begin{tabular}{|c|c|c|c|c|c|c|}
\hline S.no & Agro-ecology & Name of district & Altitude (m. ab.sl.) & Latitude and longitude & Temperature & $\begin{array}{l}\text { Rainfall } \\
\text { (mm/annum) }\end{array}$ \\
\hline 1 & Dega & Banja & 1870 to 2570 & $11^{0} 10^{\prime} \mathrm{NL}$ and $36^{\circ} 15^{\prime} \mathrm{EL}$ & $9.4-26^{0} \mathrm{C}$ & 1215.3 \\
\hline 2 & Woina Dega & Guangua & $1600-1710$ & $11^{0} \mathrm{NL} 36^{0} 19^{\prime} 60^{\prime \prime}$ E Lon & $15-27^{0} \mathrm{c}$ & $1300-1800$ \\
\hline 3 & Kolla & Jawi & 648 to 1300 & $10^{0} 38^{\prime} \mathrm{N}$ to $10^{0} 85 ; \mathrm{N}$ Long and $36^{\circ} \mathrm{E}$ to $37^{\circ} \mathrm{E}$ Lat & $25-35^{\circ} \mathrm{C}$ & $400-800$ \\
\hline
\end{tabular}

According to the Awi Zone department of agriculture, 2018 report, the Awi zone is one of the productize Zone in the Amhara region having better rainfall distribution and irrigation practices. From the total area of Zone (8935520 ha) of land 297133 ha (33.25\%) is used for farm practices. However, most of the area in the Awi zone is $34.02 \%$ (76554 ha plantation, 277842 ha natural forest) is covered with forest area. Rangeland and grazing land cover $24.3 \%$ ( 217138 ha) area of land from the total area and other land uses like infrastructure and settlement cover $8.38 \%$ (74853 ha) area land.

Table 2

Forest cover of study areas [10]

\begin{tabular}{|lllllllcl} 
S.no & $\begin{array}{l}\text { Agro- } \\
\text { ecology }\end{array}$ & $\begin{array}{l}\text { Name of } \\
\text { district }\end{array}$ & $\begin{array}{l}\text { Total } \\
\text { area(ha) }\end{array}$ & $\begin{array}{l}\text { Area of natural } \\
\text { forest }\end{array}$ & $\begin{array}{l}\text { cover } \\
(\%)\end{array}$ & $\begin{array}{l}\text { Area of } \\
\text { plantation(ha) }\end{array}$ & $\begin{array}{l}\text { cover } \\
(\%)\end{array}$ & $\begin{array}{l}\text { Total forest cover } \\
(\%)\end{array}$ \\
\hline 1 & Dega & Banja & 47915.82 & 2679 & 5.6 & 18752.7 & 39.13 & 44.7 \\
\hline 2 & Woina Dega & Guangua & 107195.24 & 21956 & 20.5 & 8976.4 & 8.4 & 28.8 \\
\hline 3 & Kolla & Jawi & 332671.2 & 162775 & 48.9 & 2663.5 & 4.8 \\
\hline
\end{tabular}

(Sources: Awi Zone department of agriculture, 2021 annual report) [10]

\section{Sampling techniques and data collection}

First, Awi zone was clustered in three agro-ecologies as Highland (2129-3600), Mid-altitude (1340-2200), and Lowland (500-1300) m.ab.sl [11], [12]. In each agroecology, one district was selected purposively having the potential of natural forest resources. In each district, natural forests were selected based on the area of forest having ( $>0.5$ ha) to get appropriate biophysical data [13]. Then from each forest community, systematic sampling with the random start was applied for biophysical data collection. Then transects and quadrates were laid with GPS application based on the forest coverage. The distance between transect was $400 \mathrm{~m}$ and the distance between quadrates was $250 \mathrm{~m}$. Transects were laid along the elevation gradient and the quadrates were laid following transects. The size of the main quadrates was $20 \mathrm{~m}$ by $20 \mathrm{~m}$ for trees having DBH $>5 \mathrm{~cm}$ [14]. Totally 76 quadrates were studied in 9 forest communities.

In 9 forest communities and 76 quadrates, height in hypsometer, diameter in diameter tape, environmental gradients by GPS, and other observation notes were collected for forest carbon stock dynamics evaluation.

\section{Data analysis}

The above-ground biomass of woody species having the DBH $>-5 \mathrm{~cm}$ was computed with five allometric equations and compared with each other. Then select the optimum allometric equation with easiness of calculation was selected.

Table 3

allometric models for above-ground biomass estimation

\begin{tabular}{|c|c|c|c|}
\hline No & Allometric models & Reference & Remark \\
\hline 1 & $A B G[K g]=0.0673\left(W D * D B H^{2 *} H\right)^{0.976}$ & \multirow[t]{2}{*}{ (Chave et al., 2014) } & For tropical moist forest \\
\hline 2 & AGB $=0.0559\left(p D^{2} H\right)$ & & For tropical dry forest \\
\hline 3 & $A G B=\exp \left(-2.4090+0.9522 \ln \left(p D^{2} H\right)\right)$ & [16] & For tropical forest \\
\hline 4 & $A G B=34.4703-8.0671(D B H)+0.6589\left(\mathrm{DBH}^{2}\right)$ & (Bhishma et al., 2010) & For all tropical forests \\
\hline
\end{tabular}

Where: AGB: Above-Ground Biomass in Kg; WD or p: wood Density; DBH or D: Diameter at Breast Height in cm; H: Height in hypsometer. The wood-specific density was taken from (Ethiopia's forest reference level submission to the UNFCCC, 2016) guideline. To simplify the process for estimating below-ground biomass, it is recommended that) the root-to-shoot ratio value of 1:5 is used; that is, to estimate below-ground biomass as $20 \%$ of above-ground tree biomass (Bhishma et al., 2010) and (Bazezew et al., 2015). Soil organic carbon was determined with SOC = BD * D * \% OC where SOC: Soil Organic Carbon, BD: Bulk Density, D: soil Depth, \%OC: Carbon concentration in the soil under forest.

BGB $=0.2^{\star}$ AGB Where: $B G B$ : below-ground biomass in $\mathrm{Kg}$; TB=AGB + BGB; TB: total biomass in $\mathrm{Kg}$. The soil parameters like organic carbon and bulk density were analyzed at a lab laboratory based on the [20] manual. 
Then inferential and descriptive statistics were analyzed Finally, data were analyzed with R Ver.3.1, XLSTAT, and SPSS Ver.25 via carbon as an overall pool and multivariate analysis of variance for carbon stock of forest communities with environmental patterns.

\section{Results}

Height and diameter showed a significant strong positive correlation $(p<0.0001)$ in all studied forest communities. The linear regression shows that diameter expresses $63 \%$ of the tree height (Fig. 2).

The principal component analysis and scatter matrices show that there is a significant difference $(p<0.001)$ of carbon stock between allometric equations. Three allometric equations [16], [21], [22] have almost similar carbon stock results, but Chave 2 (Table 3) recorded higher biomass and seems like overestimated the carbon stock of forest communities (Fig. 3).

There was a significant difference $(\mathrm{p}<0.001)$ of above-ground biomass, below-ground biomass, carbon stock, and $\mathrm{CO}_{2}$ sequestration potential across forests

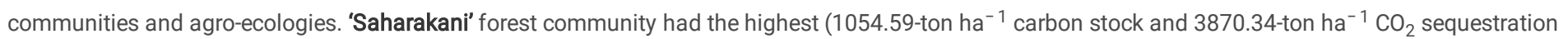
potential) followed by 'Gubel' forest community (829.88-ton ha-1 carbon stock and 3045.68-ton ha-1 $\mathrm{CO}_{2}$ sequestration potential) and 'Elala*' forest community (648.27-ton ha-1 carbon stock and 2379.16-ton ha-1 $\mathrm{CO}_{2}$ sequestration potential). The forest communities having lower carbon stock (76.89-ton ha ${ }^{-1}$ carbon stock and 282.18-ton ha ${ }^{-1} \mathrm{CO}_{2}$ sequestration potential) was the 'Ambaser' forest community which is located in lowland agro-ecology. In terms

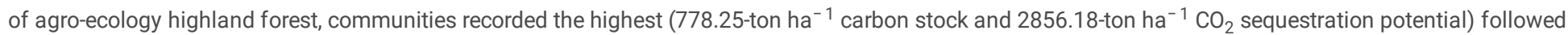
by mid-altitude forest communities (471.74-ton ha ${ }^{-1}$ carbon stock and 1731.33-ton ha- ${ }^{-1} \mathrm{CO}_{2}$ sequestration potential), and the least was lowland forest communities (286.75-ton ha-1 carbon stock and 1052.38-ton ha- ${ }^{-1} \mathrm{CO}_{2}$ sequestration potential) (Table 4). Within agro-ecology 'Saharakani' forest has higher in highland, 'Elala' forest in mid-altitude, and 'Abuhay Dengara' in lowland forest (Table 4).

Table 4

Woody species biomass and carbon stock in Ton/ha

\begin{tabular}{|c|c|c|c|c|c|c|}
\hline Agro-ecology & Forest community & AGB & BGB & TB & Carbon stock & CO2 seq \\
\hline \multirow[t]{3}{*}{ Highland } & Darkan & 798.37 & 159.67 & $958.05^{\mathrm{D}}$ & $450.28^{\mathrm{D}}$ & $1652.53^{\mathrm{D}}$ \\
\hline & Gubel & 1471.43 & 294.29 & $1765.71^{\mathrm{B}}$ & $829.88^{B}$ & $3045.68^{B}$ \\
\hline & Saharakani & 1869.84 & 373.97 & $2243.81^{A}$ & $1054.59^{A}$ & $3870.34^{A}$ \\
\hline \multirow[t]{3}{*}{ Mid-altitude } & D/Maryam & 508.53 & 101.71 & $610.23^{\mathrm{E}}$ & $286.81^{\mathrm{E}}$ & $1052.59^{\mathrm{E}}$ \\
\hline & Dukima & 851.35 & 170.27 & $1021.63^{D}$ & $480.16^{\mathrm{D}}$ & $1762.20^{\mathrm{D}}$ \\
\hline & Elala & 1149.42 & 229.88 & $1379.30^{C}$ & $648.27^{C}$ & $2379.16^{C}$ \\
\hline \multirow[t]{4}{*}{ Lowland } & Asech & 690.66 & 138.13 & $828.79^{D}$ & $389.53^{\mathrm{D}}$ & $1429.58^{D}$ \\
\hline & Ambaser & 136.32 & 27.26 & $163.59^{F}$ & $76.89^{F}$ & $282.18^{F}$ \\
\hline & Abuhay Dengara & 698.29 & 139.66 & $837.95^{\mathrm{D}}$ & $393.84^{D}$ & $1445.39^{D}$ \\
\hline & Mean & 908.25 & 181.65 & 1089.90 & 512.25 & 1879.96 \\
\hline \multicolumn{2}{|c|}{ Significance $(p<0.05)$} & Ns & ns & $\star \star$ & $\star \star$ & ** \\
\hline
\end{tabular}

Regarding the slope gradient, there was a significant difference $(\mathrm{p}<0.003)$ among above-ground biomass, below-ground biomass, carbon stock, and $\mathrm{CO}_{2}$

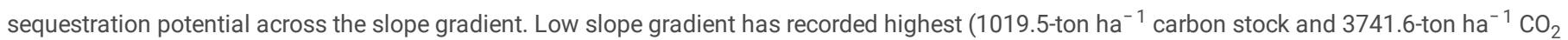
sequestration potential) followed by the steep slope (619.7-ton ha-1 carbon stock and 2274.4-ton ha-1 $\mathrm{CO}_{2}$ sequestration potential) and medium slope (472.2-ton ha-1 carbon stock and 1732.8-ton ha-1 $\mathrm{CO}_{2}$ sequestration potential) (Table 5). 
Table 5

Carbon stock in different forest communities and slope patterns

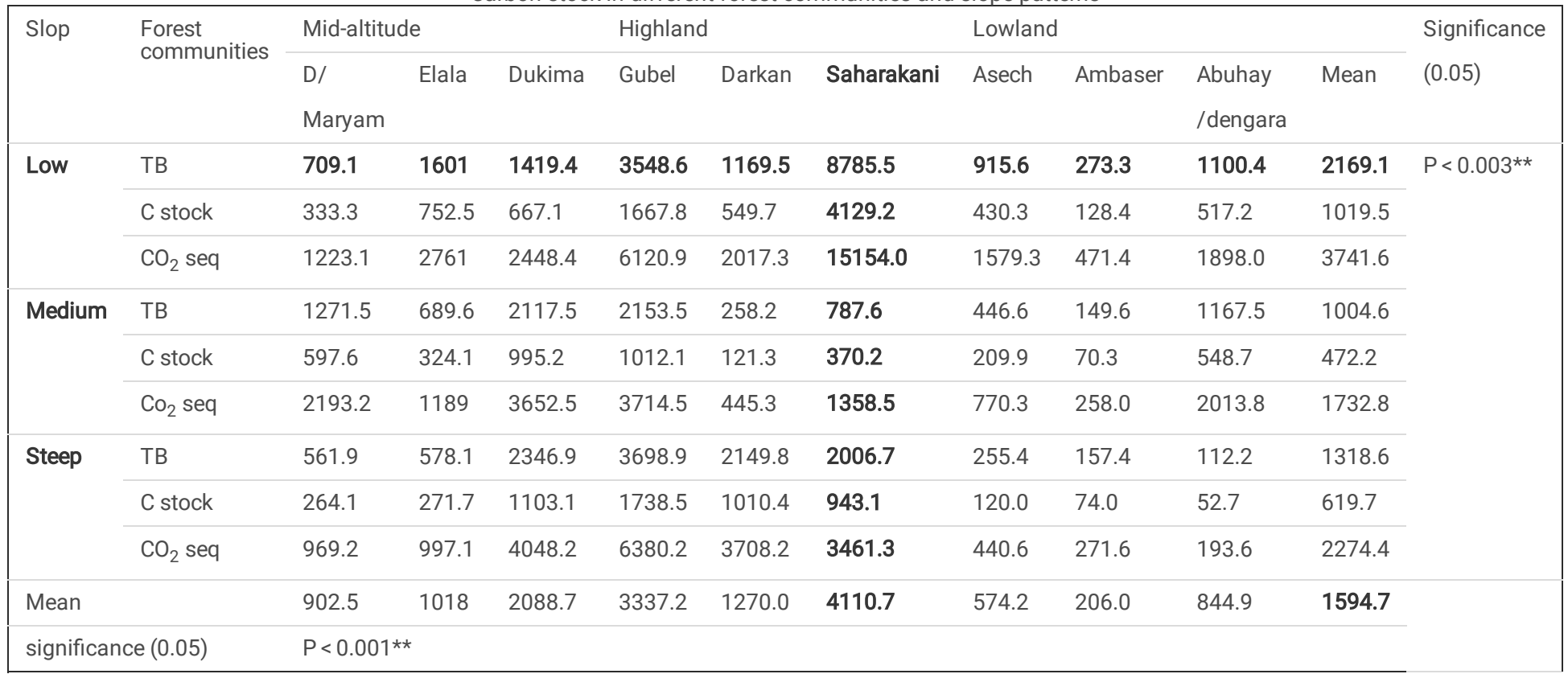

There was a significant difference ( $p>0.038$ ) of $\mathrm{CO} 2$ sequestration potential among altitude but not a significant difference $(p>0.57)$ of total biomass and carbon stock. Lower altitude has recorded the highest $\mathrm{CO}_{2}$ sequestration potential (2253.5-ton ha-1) followed by medium altitude (1923.1-ton ha-1) and higher altitude (890.1-ton ha-1) (Fig. 4).

There is a significant difference $(p<0.04)$ of carbon pools among aspect gradients. South facing had the highest carbon stock as overall pools followed by east-facing and west-facing and the least is north facing (Table 6).

Table 6

Carbon pool dynamics in aspect gradient.

\begin{tabular}{|c|c|c|c|}
\hline Aspects & $\begin{array}{l}\text { Total Biomass } \\
(\text { Ton ha-1) }\end{array}$ & Carbon stock (Ton ha-1) & $\begin{array}{l}\mathrm{CO}_{2} \text { sequestration } \\
(\text { Ton ha-1) }\end{array}$ \\
\hline North & $1153.4^{\mathrm{CD}}$ & $542.1^{C D}$ & $1989.4^{C D}$ \\
\hline South & $1647.3^{A}$ & $774.2^{\mathrm{A}}$ & $2841.4^{\mathrm{A}}$ \\
\hline East & $1439.2^{B}$ & $674.4^{B}$ & $2482.3^{B}$ \\
\hline West & $1361.4^{\mathrm{BC}}$ & $639.9^{\mathrm{BC}}$ & $2348.3^{\mathrm{BC}}$ \\
\hline North East & $1286.2^{C}$ & $604.5^{\mathrm{C}}$ & $2218.5^{C}$ \\
\hline North West & $1020.5^{\mathrm{D}}$ & $479.7^{D}$ & $1760.3^{D}$ \\
\hline South East & $1592.2^{B}$ & $748.3^{B}$ & $2746.4^{B}$ \\
\hline South West & $1702.3^{A}$ & $800.1^{A}$ & $2936.3^{A}$ \\
\hline Mean & 1400.3125 & 657.9 & 2415.363 \\
\hline Significance (0.05) & * & * & * \\
\hline
\end{tabular}

There was a significant difference ( $\mathrm{p}$ < 0.029) of soil organic carbon (SOM) among forest communities. The highest SOM was recorded in 'Asech' forest (178.5-ton ha ${ }^{-1}$ ) followed by 'Darkan' forest (127.5-ton/aha ${ }^{-1}$ ) and the least was 'Elala' (96- ton/aha ${ }^{-1}$ ) (Table 7). 
Table 7

Soil property and soil organic carbon dynamics at different forests

\begin{tabular}{|c|c|c|c|c|c|}
\hline No & Forest community & $\mathrm{pH}$ & TN (\%) & $O C(\%)$ & SOC (Ton ha-1) \\
\hline 1 & Gubel & $5.48 \pm 0.03$ & $2.83 \pm 0.03$ & $0.24 \pm 0.003$ & $122.4 \pm 6.7$ \\
\hline 2 & Darkan & $5.5 \pm 0.05$ & $2.89 \pm 0.02$ & $0.25 \pm 0.000$ & $127.5 \pm 0.000$ \\
\hline 3 & Saharakani & $5.35 \pm 0.17$ & $2.88 \pm 0.035$ & $0.24 \pm 0.003$ & $122.4 \pm 6.7$ \\
\hline 4 & Den Maryam & $5.76 \pm 0.12$ & $2.6 \pm 0.06$ & $0.23 \pm 0.006$ & $117.3 \pm 1.3$ \\
\hline 5 & Elala & $6.24 \pm 0.13$ & $2.23 \pm 0.299$ & $0.19 \pm 0.02$ & $96.9 \pm 5.3$ \\
\hline 6 & Dukima & $6.09 \pm 0.13$ & $2.85 \pm 0.04$ & $0.24 \pm 0.003$ & $122.4 \pm 6.7$ \\
\hline 7 & Asech & $7.4 \pm 0.18$ & $3.4 \pm 0.04$ & $0.35 \pm 0.05$ & $178.5 \pm 0.25$ \\
\hline 8 & Ambaser & $6.9 \pm 0.15$ & $3.1 \pm 0.04$ & $0.29 \pm 0.004$ & $149.7 \pm 8.7$ \\
\hline 9 & Abuhay Dengara & $6.5 \pm 0.14$ & $2.9 \pm 0.03$ & $0.26 \pm 0.03$ & $132.6 \pm 7.9$ \\
\hline \multicolumn{2}{|c|}{ Mean } & 6.14 & 2.85 & 0.25 & 129.97 \\
\hline \multicolumn{2}{|c|}{ P-value } & 0.001 & 0.02 & 0.029 & 0.029 \\
\hline \multicolumn{2}{|c|}{ Significance } & $\star \star$ & * & * & * \\
\hline
\end{tabular}

\section{Discussion}

\section{Parameters and Allometric Equations}

Height is a major forest tree biophysical parameter important for biomass estimation. The most allometric equation uses height as one parameter to estimate the biomass and carbon of a given tree. However, it is very difficult to measure in the field due to inappropriate field tools and the difficult nature of the parameter. Thus, the regression equation is very important to easily estimate the height of a tree. Based on this the result in Fig. 2 shows two tree growth parameters which are basic for biomass and carbon estimation have positive relationships. There is a similar result by [23] which stated that in the natural forest due to the uneven-aged nature of the forest the regression is from 60 to $85 \%$, and in plantation, forest diameter expresses up to $98 \%$ of the height. This positive relation also approved that the biomass allometric equation which uses diameter and height increases the accuracy of the equation [1], [24]-[26].

Most studies with biomass and carbon estimation of forest and other agricultural land use in tropical Africa specifically Ethiopia [4], [6], [8], [24], [27]-[29] use one of the three allometric equations. More specifically Chave 1 (Table 3) equation is very popular and easy for aboveground biomass estimation [2], [30][32]. Thus, this research used Chave 1 [22] biomass allometric equation to estimate carbon stock across different forest communities in different environmental patterns.

\section{Carbon stock across the Agroecology and Forest Communities}

Saharakani and Elala forest communities had large trees both in height and diameter because it is a remote forest and somewhat intact forest community relatively. These forest communities were relatively reserved and there were participatory forest management interventions and they are inaccessible for both human and grazing intervention. The other forest communities have faced a great challenge of anthropogenic disturbances. The study forest communities relatively have the highest carbon stock as an overall pool (254-ton ha-1 to 1177-ton ha ${ }^{-1}$ ) from [33] studies (Bazezew et al., 2015b; Belay et al., 2018; Feyissa et al., 2013; Kendie et al., 2021; Mohammed Gedefaw, Teshome Soromessa, 2013; Solomon et al., 2017; Yosef, 2012) (84.5 to 639.87-ton ha ${ }^{-1}$ ) in different parts of Ethiopia in different forest communities. Furthermore, the carbon stock potential of the study forest communities was higher than tropical, subtropical, and temperate natural forests [5], [31], [36]-[39]. The study forest communities look intact on the outside that the aged large trees crown cover, however, they are degraded and open. Specifically, the highland forest communities are substituted by Acacia decurrens plantation and the lowland forest is being converted to large-scale commercial agriculture.

\section{Carbon stock across the Environmental Gradients}

Foot slope has the highest biomass, carbon stock, and $\mathrm{CO} 2$ sequestration potential which is directly related to vegetation characteristics (Diameter height and stem density). This is because foot slope has an optimum climatic and edaphic condition for most woody species. The idea was supported by [40] who stated that environmental variables like altitude aspect and slope have greater influences on carbon dynamics. It is familiar that lower slope is almost flat land having stable soil and other biophysical conditions for better vegetation growth performance. That is why there is high carbon stock at the foot slope. The question is why there is lower carbon stock in the medium slope than the steep slope? It is maybe in the medium slope there is higher human and grazing pressure which reduces the value of the forest and in a steep slope, it is inaccessible for illegal logging and grazing. However, [6] stated carbon stock of woody species has negatively correlated with slope gradients meaning carbon stock increases with the decrease of slope gradient. This indicated that a lower slope has better carbon stock followed by a medium slope and steep slope. This idea is partially similar to our result and partially contradictory. This difference is may be due to the intensity of human and grazing impact.

Total biomass, Carbon stock, and $\mathrm{CO} 2$ sequestration potential have in decreasing order with altitudinal gradient. This may be related to stem density and species diversity as well as the growth performance of woody species. In the lower altitude which is located at the foot of the forest, there is high species 
diversity, favorable soil conditions, and high stem density. The individual trees have relatively high in height and diameter. The trend of all this tree growth and edaphic condition decreases with the increase of altitude. This makes the difference in carbon stock potential within the altitudinal gradient. This idea is in line with [6] which stated that carbon stock in woody species has a strong negative correlation with altitudinal gradients which shows the carbon stock decreases with increasing altitude of a given forest community. However, there is a reverse result by [35] which stated that carbon stock overall has an increasing trend with an increasing altitudinal gradient. Scientifically, as carbon stock is directly related to growth performance and vegetation characteristics as well as site condition our result is somewhat acceptable. However, natural and anthropogenic disturbances maybe affect the relation of altitude and carbon stock whether they are negatively or positively correlated.

Southeast facing has the highest carbon stock as an overall carbon pool. Aspect factor as it is a sunlight intensity and direction highly determine the vegetation growth performance and woody species diversity which related to woody biomass and carbon stock. In most studies [4], [33], [35], [39], [41], [42] north and east-facing having strong light intensity and perpendicular light direction specifically in tropical countries have higher vegetation performance and carbon stock. However, the studies imply that this scenario depends on the anthropogenic disturbances and management intensity of the forest. In this study, most forest communities that were sampled are facing grazing and human pressure and in the south parts, some hills are inaccessible for grazing and illegal harvesting. This may be changing the ground truth that south-facing is better in carbon stock. On the other hand, woody species in the study forest select the south-facing due to the need for a slight light concentration due to climate change resulting in timberline shifts. This idea is supported by [43]-[45] that climate change shifts the timberline in terms of altitude and aspect which make most woody species in the tropics select the south and southwest facings.

\section{Soil Organic Carbon Across Forest Communities}

The study forests are situated in different agroecology resulting in environmental conditions. In addition, there is high grazing and human disturbances in the forest. These all make the forest have different soil physical and chemical characteristics. The main determinant factor for soil organic carbon is the concentration of organic carbon on the soil parameter. It is highly affected by natural and human-made disturbances. Lowland forests have better soil organic carbon may be due to the fast decomposition of litterfall from the trees and the highland forests have better vegetation growth performances. The idea is similar to [46] which stated that different forest ecosystems made soil property dynamics. Furthermore, the study by [30], [35], [41], [47], [48] across the world stated that soil organic carbon is very dynamics spatially and temporally even on a small spatial scale. It is a somewhat long-term carbon reservoir and has a great role in climate change mitigation.

\section{Conclusion}

Highland forest communities have the potential to store the largest carbon stock followed by mid-altitude forest communities and lowland forest communities that have stored the least carbon stock. This is due to woody species growth performance and anthropogenic disturbances in Lowland and Mid-altitude forests. Slope, aspect, and altitudinal gradient have an impact on carbon stock. As an overall pool at which carbon stock and slope gradient have reverse trend which means carbon stock is higher at the lower slope. In altitude gradient carbon stock decreasing order with altitudinal gradient. Southeast facing has the highest carbon stock as an overall carbon pool. Aspect factor as it is a sunlight intensity and direction highly determine the vegetation growth performance and woody species diversity which related to woody biomass and carbon stock. Lowland forests have better soil organic carbon may be due to the fast decomposition of litterfall from the trees and the highland forests have better vegetation growth performances.

The natural forest communities of the study area have a huge amount of carbon stock. This implies that the studied natural forest communities had great potential in $\mathrm{CO}_{2}$ sequestration which mitigates the crisis of climate change. The highest mean overall carbon pool (woody species and soil organic carbon) of the study area indicates that natural forests have a great potential for climate change mitigation through reducing a reasonable amount of carbon from the atmosphere. Appropriate credit is not given yet for the conservation of the natural forests and these resources are continuously declining.

Urgent conservation is required and then further plan-based sustainable conservation should be done to maintain the health of the forest ecology for climate change mitigation, socially stable community, and economically benefited communities from natural forest. To do this international organizations like REDD ${ }^{+}$ and the United Nations intergovernmental panel for climate change mitigation have to be involved based on international commitments.

\section{Abbreviations}

\% Percent

${ }^{0} \mathrm{C} \quad$ Degree centigrade

AGB Aboveground Biomass

BGB Belowground Biomass

$\mathrm{cm} \quad$ Centimeter

CO2 Carbon dioxide

DBH Diameter at Breast Height

EL East Latitude

GPS Geographical Positioning System 
OC

Organic Carbon

$\mathrm{pH}$

WD $(p) \quad$ Wood Density

\section{Declarations}

\section{Ethics approval and consent to participate}

Animals, humans, and other plant propagules were not used in this research. Thus, it is not relevant for this work.

\section{Consent for publication}

I understand that the information will be published without a name attached, but that full secrecy cannot be guaranteed. I understand that the text and any pictures published in the article will be freely available on the internet and may be seen by the general public. The pictures and text may also appear on other websites or in print, may be translated into other languages, or used for commercial purposes. I have been offered the opportunity to read the article.

\section{Competing interests}

There is no conflict of interest and copyright problem because all relevant participants in this work are included as an author.

\section{Availability of data and materials}

The datasets generated during and/or analyzed during the current study are available from the corresponding author on reasonable request.

\section{Competing interests}

There is no conflict of interest in this article and all the contributors are listed as an author

\section{Funding}

The funding organization for this study was Injibara University, Ethiopia

\section{Authors contribution}

\begin{tabular}{|lll|}
\hline S. No & Authors name & Contribution \\
\hline 1 & Melkamu Kassaye & Data collection, analysis, interpretation, writing \\
\hline 2 & Yonas Derebe & Data Collection, species identification, and editing \\
\hline 3 & Wondwossen Kibrie & Soil organic carbon data collection and analysis \\
\hline 4 & Fikadu Debebe & Soil organic carbon data collection and analysis \\
\hline 5 & Bahiru Gedamu & Data collection \\
\hline
\end{tabular}

\section{Acknowledgment}

First of all, we would like to thank Injibara University for its arrangement, funding, and other facilities. Next, we would like to thank Mr. Mulugeta Tamir for the pleasure of helping of facility and finance. Lastly, I would like to give pleasure to the university colleges and supporting staff to make this work at the end.

\section{References}

1. N. H. R. and M. Ostwald, Carbon Inventory Methods: a handbook for greenhouse gas inventory carbon mitigation and round wood production projects, 1st ed., vol. 29. Springer Science + Business Media B.V, 2008. 
2. M. Henry, "Carbon stocks and dynamics in Sub Saharan Africa," The University of Tuscia, 2010.

3. IPCC, Mitigation of climate change: Contribution of working group III to the fourth assessment report of the Intergovernmental Panel on Climate Change. 2007.

4. S. B. Mohammed Gedefaw, Teshome Soromessa, "Forest Carbon Stocks in Woody Plants of Tara Gedam Forest: Implication for Climate Change Mitigation," Annu. Rev. CyberTherapy Telemed., vol. 3, no. 1, p. 63, 2013, DOI: 10.1097/01.naj.0000529715.93343.b0.

5. Y. Malhi, "The carbon balance of tropical forest regions, 1990-2005," Curr. Opin. Environ. Sustain., vol. 2, no. 4, pp. 237-244, 2010, DOI: 10.1016/j.cosust.2010.08.002.

6. A. Dibaba, T. Soromessa, and B. Workineh, "Carbon stock of the various carbon pools in Gerba - Dima moist Afromontane forest, Southwestern Ethiopia," Carbon Balance Manag., vol. 14, no. 1, pp. 1-10, 2019, DOI: 10.1186/s13021-019-0116-x.

7. F. Abere, Y. Belete, A. Kefalew, and T. Soromessa, "Carbon stock of Banja forest in Banja district, Amhara region, Ethiopia: An implication for climate change mitigation,” J. Sustain. For., vol. 36, no. 6, pp. 604-622, 2017, DOI: 10.1080/10549811.2017.1332646.

8. M. Siraj, "Forest carbon stocks in woody plants of Chilimo-Gaji Forest, Ethiopia: Implications of managing forests for climate change mitigation," South African J. Bot., vol. 127, pp. 213-219, 2019, DOI: 10.1016/j.sajb.2019.09.003.

9. S. R. and M. van N. Kurniatun Hairiah, Sonya Dewi, Fahmuddin Agus, Sandra Velarde, Andree Ekadinata, "Measuring Carbon Stocks Across land use systems: Amanual," Bogor, Indonesia, 2010.

10. Awi ZOne Agricultural office, “Awi Zone Agricultural Offices Annual Report," Injibara, 2021.

11. T. Azene, Bekele, Useful trees and shrubs of Ethiopia: Identification, Propagation, and Management for 17 Agroclimatic Zones, 1 st ed. Nairobi, Kenya: RELMA in ICRAF Project World Agroforestry Centre, East Africa Region, Nairobi Kenya, 2007.

12. D. Gorfu and E. Ahmed, "Crops and Agroecological Zones of Ethiopia," p. 47, 2011, [Online]. Available: http://www.google.dk/url? sa=t\&rct=j\&q=\&esrc=s\&source=web\&cd=1\&ved=0CDQQFjAA\&url=http://prrp-ethiopia.org/index.php/component/phocadownload/category/1-publicdocuments?download=51:crops-and-agro-ecological-zones-total-dereje-gorfu\&ei=X91jUbLDFYH27AbBtYGgCg.

13. W. Alemayehu, “Ethiopian Church Forests: Opportunities and Challenges For Restoration,” Wageningen University, 2007.

14. Kent, Vegetation Description and Analysis: A Practical Approach, Second., vol. 159, no. 2. Atrium, Southern Gate, Chichester, West Sussex: A John Wiley \& Sons, Ltd., Publication, 2012

15. Chave et al, "Improved allometric models to estimate the aboveground biomass of tropical trees," Glob. Chang. Biol., vol. 20, pp. 3177-3190, 2014, DOI: $10.1111 /$ gcb.12629.

16. S. Brown, Estimating biomass and biomass change of tropical forests: a primer, 1st ed., vol. 134, no. August. Rome (Italy): FAo, 1997.

17. R. T. Bhishma P. Subedi, Shiva Shankar Pandey, Ajay Pandey, Eak Bahadur Rana, Sanjeeb Bhattarai, Tibendra Raj Banskota, Shambhu Charmakar, “Forest Carbon Stock Measurement Guidelines for measuring carbon stocks in community management forest," p. 66, 2010.

18. "Ethiopia's forest reference level submission to the UNFCCC," Addis Ababa, 2016.

19. M. N. Bazezew, T. Soromessa, and E. Bayable, "Above- and Below-Ground Reserved Carbon in Danaba Community Forest of Oromia Region, Ethiopia: Implications for CO 2 Emission Balance," Am. J. Environ. Prot., vol. 4, no. 2, pp. 75-82, 2015, doi: 10.11648/j.ajep.20150402.11.

20. T. B. Sahlemedhin Sertsu, "Procedures for soil and plant analysis," Addis Ababa, 74, 2000.

21. B. Subedi, S. Pandey, A. Pandey, and E. Rana, Forest Carbon Stock Measurement: Guidelines for measuring carbon stocks in community-managed forests, 1st ed., no. July. Nepal: Asia Network for Sustainable Agriculture and Bioresources, Federation of Community Forest Users, Nepa, international Centre for Integrated Mountain Development, 2010.

22. J. Chave et al., "Improved allometric models to estimate the aboveground biomass of tropical trees," Glob. Chang. Biol., vol. 20, no. 10, pp. 3177-3190, 2014, DOI: $10.1111 / \mathrm{gcb} .12629$.

23. T. G. Cole and J. J. Ewel, "Allometric equations for four valuable tropical tree species," vol. 229, pp. 351-360, 2006, DOI: 10.1016/j.foreco.2006.04.017.

24. G. Kandie, S. Addisu, and A. Abiyu, “Biomass and soil carbon stocks in different forest types, Northwestern Ethiopia," Int. J. River Basin Manag., vol. 19, no. 1, pp. 123-129, 2021, DOI: 10.1080/15715124.2019.1593183.

25. S. Kuyah, J. Dietz, and C. Muthuri, "Allometry and partitioning of above- and below-ground biomass in farmed eucalyptus species dominant in Western Kenyan agricultural landscapes," biomass and bioenergy, vol. 55, pp. 276-284, 2013.

26. K. P. Freier, B. Glaser, and W. Zech, "Mathematical modeling of soil carbon turnover in natural Podocarpus forest and Eucalyptus plantation in Ethiopia using compound-specific $\delta 13 C$ analysis," Glob. Chang. Biol., vol. 16, no. 5, pp. 1487-1502, 2010, doi: 10.1111/j.1365-2486.2009.02096.x.

27. M. Meragiaw, B. R. Singh, Z. Woldu, and V. Martinsen, "Carbon stocks of above- And belowground tree biomass in Kibate Forest around Wonchi Crater Lake, Central Highland of Ethiopia," PLoS One, vol. 16, no. 7 July, pp. 8-11, 2021, DOI: 10.1371/journal.pone.0254231.

28. N. Solomon, E. Birhane, T. Tadesse, A. C. Treydte, and K. Meles, "Carbon stocks and sequestration potential of dry forests under community management in Tigray, Ethiopia," Ecol. Process., vol. 6, no. 1, 2017, DOI: 10.1186/s13717-017-0088-2.

29. M. N. Bazezew, T. Soromessa, and E. Bayable, "Above- and Below-Ground Reserved Carbon in Danaba Community Forest of Oromia Region, Ethiopia: Implications for CO 2 Emission Balance," vol. 4, no. 2, pp. 75-82, 2015, DOI: 10.11648/j.ajep.20150402.11.

30. T. Toru and K. Kibret, "Carbon stock under major land use/land cover types of Hades sub-watershed, eastern Ethiopia," Carbon Balance Manag., vol. 14, no. 1, pp. 1-14, 2019, DOI: 10.1186/s13021-019-0122-z.

31. S. M. NIZAMI, “Estimation of Carbon Stocks in Subtropical," Arid Agriculture University Rawalpindi, 2010.

32. IPCC, "2006 IPCC Guidelines for National Greenhouse Gas Inventories," IGES, Japan, 2006.

Page 9/12 
33. B. Belay, E. Pötzelsberger, and H. Hasenauer, "The carbon sequestration potential of degraded agricultural land in the Amhara region of Ethiopia," Forests, vol. 9, no. 8, pp. 1-23, 2018, doi: 10.3390/f9080470.

34. B. A. YOSEF, "Carbon stock potentials of woodlands and land use and land cover changes in Northwestern lowlands of Ethiopia," Hawassa University, 2012.

35. A. Feyissa, T. Soromessa, and M. Argaw, “Forest Carbon Stocks and Variations along Altitudinal Gradients in Egdu Forest: Implications of Managing Forests for Climate Change Mitigation,” Sci. Technol. Arts Res. J., vol. 7522, no. 4, pp. 40-46, 2013.

36. D. V. I. J. Payton, A. V. T. T. S. N. E. Weeks, and Addis, "Carbon baseline and Mechanisms for payments for carbon environmental services from protected areas in Ethiopia," Addis Ababa, Ethiopia, 2012.

37. K. Macdicken, G. Reams, and J. De Freitas, "Introduction to the Changes in Global Forest Resources from 1990 to 2015," For. Ecol. Manage., vol. 352, pp. 1-2, 2015, DOI: 10.1016/j.foreco.2015.06.018.

38. R. Jindal, B. Swallow, and J. Kerr, “Forestry-based carbon sequestration projects in Africa: Potential benefits and challenges," Nat. Resour. Forum, vol. 32, pp. 116-130, 2008.

39. E. Alvarez, A. Duque, J. Saldarriaga, K. Cabrera, and G. De, "Tree above-ground biomass allometries for carbon stocks estimation in the natural forests of Colombia Esteban,” For. Ecol. Manage., vol. 267, 2012, doi: 10.1016/j.foreco.2011.12.013.

40. G. Yilma and A. Derero, "Carbon stock and woody species diversity patterns in church forests along church age gradient in Addis Ababa, Ethiopia," Urban Ecosyst., p. 15, 2020, DOI: 10.1007/s11252-020-00961-z.

41. X. Liu, R. Ekoungoulou, J. J. Loumeto, S. A. Ifo, and Y. E. Bocko, "Evaluation of carbon stocks in above- and below-ground biomass in Central Africa: a case study of Lesio-louna tropical rainforest of Congo," Biogeosciences Discuss, vol. 11, 2014, DOI: 10.5194/bgd-11-10703-2014.

42. Z. G. and S. Z. Genene Assefa, Tefera Mengistu, "Forest carbon pools and carbon stock assement in the context of SFM and REDD+." HAWASSA UNIVERSITY WONDO, Wondo Genet, Ethiopia, p. 74, 2013.

43. T. Payn et al., "Changes in planted forests and future global implications," For. Ecol. Manage., vol. 352, pp. 57-67, 2015, DOI: 10.1016/j.foreco.2015.06.021.

44. M. A. Ju and S. M. Turton, "Climate Change Effects on Community Forests: Finding Through User 's Lens and Local Knowledge," Small-scale For., 2014, DOI: $10.1007 /$ s11842-014-9264-8.

45. B. Alemu, "The Role of Forest and Soil Carbon Sequestrations on Climate Change Mitigation," vol. 3, no. 10, pp. 492-505, 2014.

46. G. Dalle, "Relationships between vegetation composition and environmental variables in the Borana rangelands, southern Oromia, Ethiopia AND ENVIRONMENTAL VARIABLES IN THE BORANA," no. January 2015, 2014.

47. D. Nsabimana, "Carbon stock and fluxes in Nyungwe forest and Ruhande Arboretum in Rwanda," UNIVERSITY OF GOTHENBURG, 2009.

48. R. Lal, "Soil Carbon Sequestration Impacts on Global Change and Food Security," Science (80-.)., vol. 1623, no. 2004, 2008, DOI: 10.1126/science.1097396.

\section{Figures}




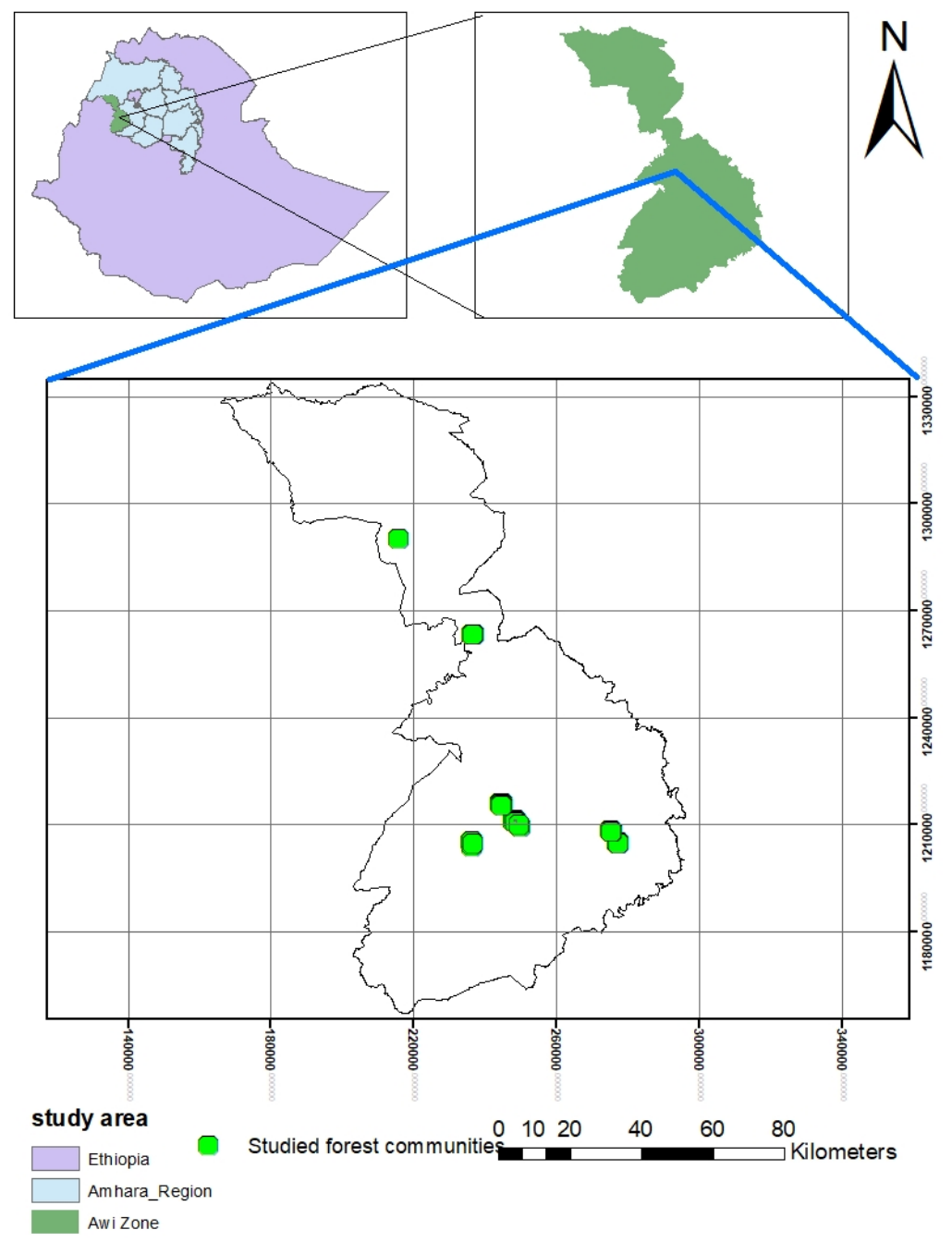

Figure 1

Map of the study area

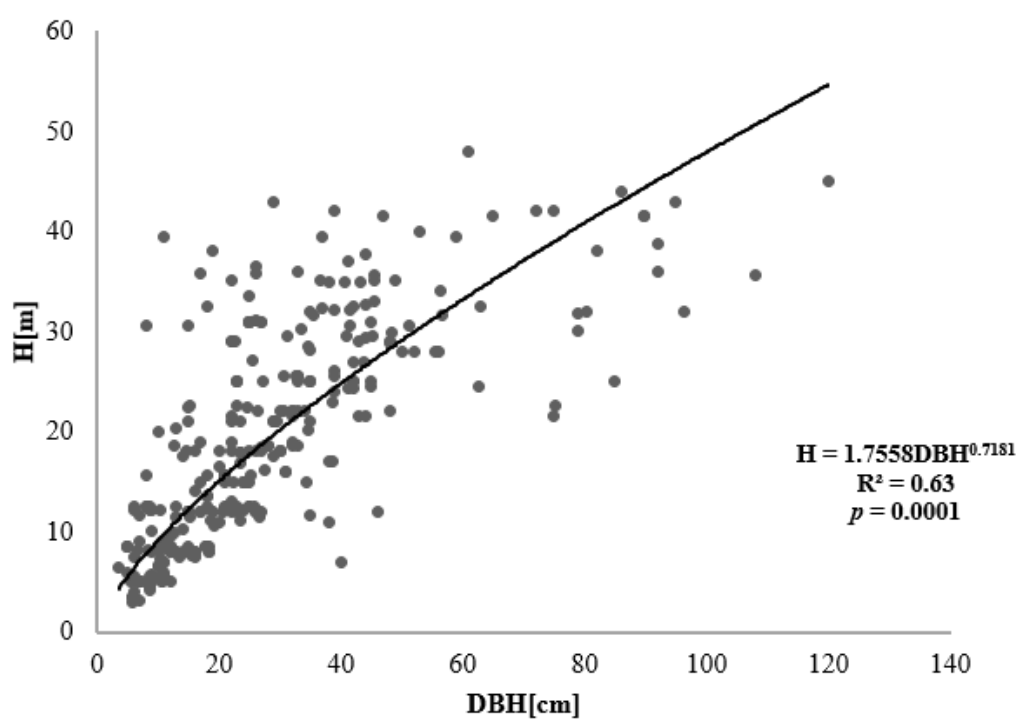

Figure 2

Diameter and Height correlation 


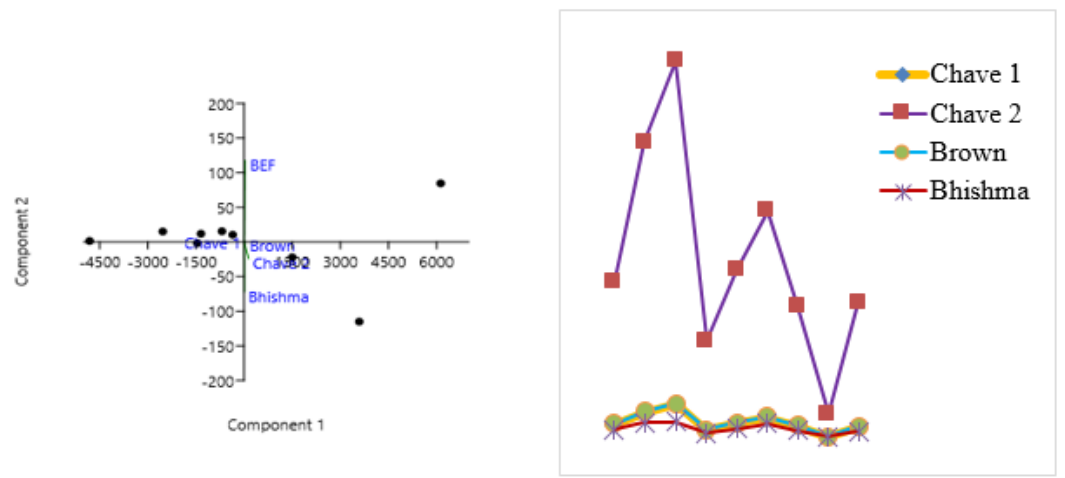

Figure 3

Biomass allometric equations

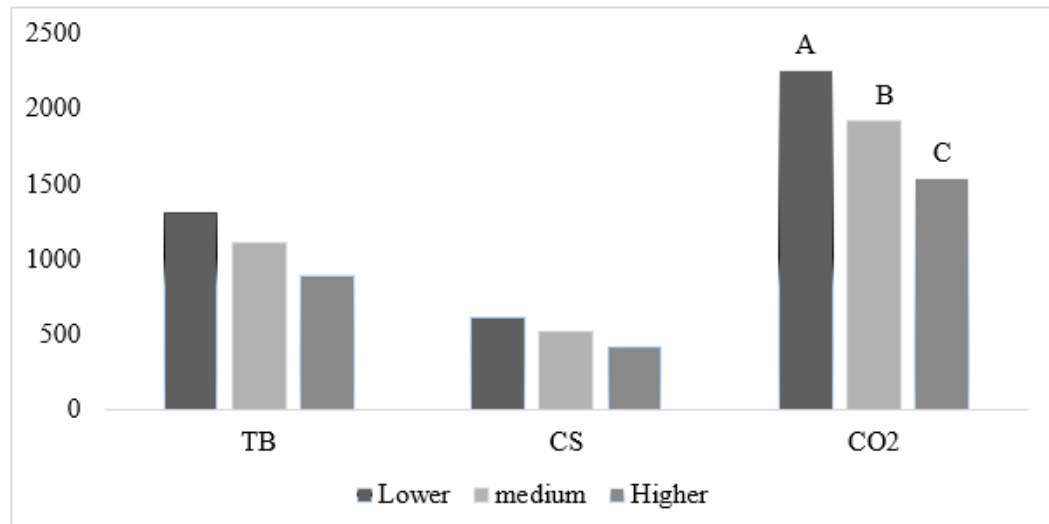

Figure 4

Carbon stock dynamics in altitude gradient 